\title{
Use of the nursing intervention classification for identifying the workload of a nursing team in a surgical center ${ }^{1}$
}

\author{
João Francisco Possari² \\ Raquel Rapone Gaidzinski ${ }^{3}$ \\ Antônio Fernandes Costa Lima ${ }^{4}$ \\ Fernanda Maria Togeiro Fugulin ${ }^{5}$ \\ Tracy Heather Herdman ${ }^{6}$
}

Objective: to analyze the distribution of nursing professionals' workloads, according to the Nursing Intervention Classification (NIC), during the transoperative period at a surgical center specializing in oncology. Methods: this was an observational and descriptive cross-sectional study. The sample consisted of 11 nurses, 25 nursing technicians who performed a variety of roles within the operating room, 16 nursing technicians who worked with the surgical instrumentation and two nursing technicians from patient reception who worked in the surgical center during the transoperative period. An instrument was developed to collect data and the interventions were validated according to NIC taxonomy. Results: a total of 266 activities were identified and mapped into 49 nursing interventions, seven domains and 20 classes of the NIC. The most representative domains were Physiological-Complex (61.68\%) and Health System (22.12\%), while the most frequent interventions were Surgical Care (30.62\%) and Documentation $(11.47 \%)$, respectively. The productivity of the nursing team reached $95.34 \%$. Conclusions: use of the Nursing Intervention Classification contributes towards the discussion regarding adequate, professional nursing staffing levels, because it shows the distribution of the work load.

Descriptors: Nursing; Nursing Care; Nursing Staff; Personnel Management; Workload.

\footnotetext{
1 Paper extracted from doctoral dissertation "Nursing staff in a specialized oncology surgical center: analysis of the intervention indicators", presented to Escola de Enfermagem, Universidade de São Paulo, São Paulo, SP, Brazil. Supported by Fundação de Amparo à Pesquisa do Estado de São Paulo (FAPESP), Brazil, process \# 2010/10010-5.

2 PhD, RN, Departamento Geral de Assistência, Instituto do Câncer do Estado de São Paulo, São Paulo, SP, Brazil.

${ }^{3} \mathrm{PhD}$, Full Professor, Escola de Enfermagem, Universidade de São Paulo, São Paulo, SP, Brazil.

${ }^{4} \mathrm{PhD}$, Professor, Escola de Enfermagem, Universidade de São Paulo, São Paulo, SP, Brazil.

5 PhD, Associate Professor, Escola de Enfermagem, Universidade de São Paulo, São Paulo, SP, Brazil.

${ }^{6} \mathrm{PhD}$, Researcher, NANDA International, Massachusetts, Boston, United States.
}

Corresponding Author: João Francisco Possari

Instituto do Câncer do Estado de São Paulo

Diretoria Geral de Assistência

Av. Dr. Arnaldo, 251

Bairro: Cerqueira Cesar

CEP: 01246-000, São Paulo, SP, Brasil

E-mail: jfpossari@ig.com.br
Copyright () 2015 Revista Latino-Americana de Enfermagem This is an Open Access article distributed under the terms of the Creative Commons Attribution Non-Commercial License (CC BY-NC).

This license lets others distribute, remix, tweak, and build upon your work non-commercially, and although their new works must also acknowledge you and be non-commercial, they don't have to license their derivative works on the same terms. 


\section{Introduction}

In healthcare organizations, the need to decrease costs and increase service provision puts into question professional nursing staffing levels, since these organizations have greater numbers of nursing professionals than those of other professionals and, consequently, nursing professionals represent the greatest operational cost for these organizations ${ }^{(1-2)}$.

Several studies have considered nursing workload in intensive care units, with a variety of tools including the Therapeutic Intervention Scoring System - 28 (TISS-28) and the Nursing Activities Score (NAS) ${ }^{(3-5)}$. Authors developed a human factors model for workload specifying workload at three distinct levels of analysis, in addition to multiple nurse and patient outcomes(6). Studies have identified that an increased workload with fewer registered nurses, and unstable nursing unit environments were linked to negative patient outcomes, including falls and medication errors on medical/surgical units $^{(7)}$. Studies have also been conducted in community health nursing, exploring the dependency levels of elderly clients and the impact on nursing workload(8-9).

Many studies have noted the linkage between nursing workload and nurses' quality of working life and quality/safety of care, including patient mortality (3,6,10-11). In a study that evaluated the association of nurse staffing, nurses' education, and the nurse work environment on patient outcomes; they found that each additional patient added to the workload of a hospital staff nurse was associated with a $7 \%$ increase in both mortality and failure to rescue following common surgical procedures ${ }^{(10)}$. A similar association between staffing and mortality was found in English hospitals ${ }^{(11)}$.

Studies have identified an association between a high nurse-to-bed ratio and low surgical mortality(10,12-14). Although these studies contributed towards this field of knowledge and provide evidence to support the importance of appropriate nursing workload in the surgical center environment, there is a need to identify the interventions and activities on which nursing professionals spend time, during the transoperative period, from the moment when the patient is received at the surgical center until his/her transfer to PostAnesthetic Recovery (PAR).

The standard of nursing care in surgical centers, during the transoperative period, is a direct reflection of the staffing level policy. Therefore, it is essential to set adequate human resource levels, with a skill profile sufficient for safely caring for these patients. Knowledge of the distribution of time spent on nursing interventions and activities that are directed towards patients, in anesthetic-surgical procedures, may strengthen the arguments regarding adequate professional staffing levels and in representations for decision-making bodies in healthcare organizations.

Nursing interventions during the transoperative period have become complex over recent last years, due to the great technological advances and new surgical and anesthetic techniques. These make it necessary for the nursing team to constantly go through training and updating, in order to efficiently care for patients undergoing anesthetic-surgical interventions. It also supports the need to determine, using evidence from research, which interventions can be delegated to support staff, under nursing supervision, and which require a professional nurse in order to obtain the best possible outcomes for the patient.

From this perspective, use of the Nursing Intervention Classification (NIC) supports workforce planning and evaluation by identifying the nursing workload, expressed in interventions, classes and domains and it has been used in different contexts where nursing care occurs. An integrative review shows that in line with the challenge of expanding the use of NIC, studies that have used it as a basis for measuring workload have been an important resource in supporting workforce planning; however, the review identified that only Brazil has used it for this purpose where issues of nursing workforce size have been a source of conflict among managers ${ }^{(15)}$.

The NIC may constitute an important theoreticalmethodological reference point for mapping out the nursing interventions and activities carried out during the transoperative period, with the aim of identifying the workload. By identifying the interventions that are most used among certain groups of patients, it is possible to establish the resources needed, level of care, category of the professionals involved, time taken, cost and efficiency. It is emphasized that identifying nursing interventions is the first step towards greater future efficiency in planning and using resources ${ }^{(16)}$. A review of PubMed for the past ten years found only one study which sought to determine the utility of the NIC terminology to classify nursing care interventions of a nursing workload measure(17). The authors compared the time to complete nursing interventions and the NIC published times, and explored which care interventions could be expected to occur routinely at an orthopedic surgical unit ${ }^{(17)}$. No studies could be found that considered NIC, nursing workload and surgical oncology. 


\section{Objective}

The objective of this study was to analyze the workload distribution of nursing professionals relating to interventions and activities, according to the NIC, during the transoperative period in a surgical center that specializes in oncology.

\section{Method}

This was a quantitative, observational and descriptive cross-sectional study, conducted at the surgical center of the Cancer Institute of the State of Sao Paulo (Instituto do Câncer do Estado de São Paulo - ICESP), which is a tertiary-level hospital located in the city of São Paulo, Brazil. ICESP was chosen as the location to conduct this study because of the importance of oncology within the Brazilian healthcare setting and around the world, given that cancer is the second leading cause of death, and due to the lack of studies on human resource planning in this field.

The sample size needed to determine the frequency with which interventions/activities of the nursing professionals appear during operation of the surgical center was predetermined considering the following criteria: the $95 \%$ confidence interval; an error of $5 \%$ of the average sampled value and the mean value of the population; a range of $15 \mathrm{~min}$ between samples; the ratio (probability) at which each intervention/ activity appears; interventions/activities often such that $<1 / 1000$ were not considered; the sample size value equaling 1000 was obtained by extrapolating the values of $>15$ categories (operations) of those proposed for the multinomial distribution, the working day has $1440 \mathrm{~min}$ divided into 4 turns, with a duration 360 min each.

Quantity daily average/turns professional category that make up the surgical center nursing team for the perioperative period was calculated by the average number of professionals working at every turn.

The project was approved by the Research Ethics Committee of the Nursing School of the University of Sao Paulo (USP), process n0884/2009 and the data collection was authorized by the Clinical Board of ICESP (process n0611/2010). Confidentiality of patients and nurses was assured by the absence of patient or nurse identifiers on any data collection form.

The study was conducted according to the following stages:

Development and validation of the instrument "Interventions/Activities of Nursing Professionals in
Surgical Center (Identification and mapping of the activities): the set of activities performed by the nursing professionals was obtained through reports in the patient records and through direct observation of the nursing professionals. This set of activities was classified in one of three categories: nursing interventions, associated activities and personal activities. Nursing interventions included both direct and indirect care, in accordance with the NIC. Associated activities included those activities that did not require performance by a nursing professional, but that were associated with nursing work. Activities relating to pauses in the nurses' work in order to attend to the physiological needs and to rest were classified as personal.

The cross-referenced mapping technique(18) was used to classify the activities as direct or indirect care interventions. The direct care interventions referred to treatments implemented through interaction with the user (patient/family). These nursing actions were thus characterized as being of a physiological and psychosocial nature, which comprised practical actions and support and counseling actions ${ }^{(16)}$. The indirect care interventions consisted of treatments that were not performed in the proximity of the user, but were conducted for his/her benefit. These activities included actions relating to the management of the unit and to interdisciplinary collaboration ${ }^{(16)}$.

Three workshops were conducted so that the nurses and nursing technicians of the surgical center of ICESP could validate the intervention sets and activities that were obtained, regarding the adequacy, understanding and scope of these interventions and the activities that were performed by nursing professionals. After content validation, a register for measuring the time spent by the nursing professionals to perform interventions and activities during the transoperative period was constructed.

A structured, work sampling technique was used in this study, with a periodic interval of 15 minutes, to measure the time spent by the nursing professionals on each activity or intervention.

The sample consisted of 11 nurses, 25 nursing technicians, who performed a variety of roles within the operating room, 16 nursing technicians, who worked with the surgical instrumentation and two nursing technicians from patient reception who worked in the surgical center during the transoperative period, during the morning and afternoon shifts.

Data collection occurred between August 16 and 20, 2010. Data was collected through a specifically 
built instrument that contains two columns in a list of nursing interventions/activities and in the other place to record the observations of the work performed in 15 min intervals. Each day, after data collection was concluded, the records from the registers were input into electronic worksheets, in order to facilitate the verification and reorganization of data, and to permit the necessary calculations. Interventions or activities that were not sampled, or that were only sampled once, were disregarded.

\section{Results}

Most of the sample participants were female and under 30 years of age, with less than five years as trained professionals, and less than three years working at ICESP.

The direct and indirect care activities validated by the nurses and nursing technicians who participated in the workshops, and who represented the operating room, surgical instrumentation, and patient reception areas, resulted in a list of 266 nursing activities. These activities were analyzed and mapped into 49 nursing interventions, seven domains and 20 classes, in accordance with the NIC.
The distribution of the 4831 intervention samples and activities performed by the nurses and nursing technicians working in the three previously identified surgical areas can be seen in Table 1. An association between the type of intervention (direct or indirect) or activity and the professional category was observed. The nursing technicians working in surgical instrumentation performed a significantly greater number of direct care interventions than were performed by the other professionals.

Tables 2 and 3 present the percentages of time spent by the nursing team in carrying out the direct and indirect care interventions. There were 99 samples $(2.05 \%)$ of associated activities performed by the nursing team. The most frequent of these activities was telephone calls to other professionals or services. There were 225 samples (4.66\%) of personal activities relating to attending to physiological needs (eating and evacuating).

Table 4 shows the percentage distribution of work time spent by the nurses and nursing technicians working in the perioperative environments of the operating room (OR), surgical instrumentation (SI), and patient reception (PR) in performing nursing interventions, in accordance with the domains of the NIC.

Table 1 - Distribution of the interventions and activities performed by nursing professionals in the perioperative environments at the surgical center. Sao Paulo, SP, Brazil, 2011

\begin{tabular}{|c|c|c|c|c|c|c|c|c|}
\hline \multirow{2}{*}{ Interventions / Activities } & \multicolumn{2}{|c|}{ Nurse } & \multicolumn{2}{|c|}{$\begin{array}{c}\text { Nursing Technician } \\
\text { (OR)* }\end{array}$} & \multicolumn{2}{|c|}{$\begin{array}{c}\text { Nursing Technician } \\
(\mathrm{SI})^{\dagger}\end{array}$} & \multicolumn{2}{|c|}{ Nursing Technician (PR) } \\
\hline & $\mathbf{n}$ & $\%$ & $\mathbf{n}$ & $\%$ & $\mathbf{n}$ & $\%$ & $\mathbf{n}$ & $\%$ \\
\hline Direct Care Intervention & 380 & 42.79 & 1268 & 64.27 & 1641 & 94.85 & 137 & 57.08 \\
\hline Indirect Care intervention & 373 & 42.00 & 601 & 30.46 & 38 & 2.20 & 69 & 28.75 \\
\hline Associated Activities & 71 & 8.00 & 9 & 0.45 & - & - & 19 & 7.92 \\
\hline Personal Activities & 64 & 7.21 & 95 & 4.82 & 51 & 2.95 & 15 & 6.25 \\
\hline Total & 888 & 100.00 & 1973 & 100.00 & 1730 & 100.00 & 240 & 100.00 \\
\hline
\end{tabular}

* OR - Operating Room; + SI - Surgical Instrumentation; ₹ PR - Patient Reception

Table 2 - Distribution of the direct care interventions carried out by nursing professionals at the surgical center of ICESP. Sao Paulo, SP, Brazil, 2011

\begin{tabular}{|c|c|c|c|c|c|c|c|c|}
\hline \multirow{2}{*}{ Direct care interventions } & \multicolumn{2}{|c|}{ Nurse } & \multicolumn{2}{|c|}{$\begin{array}{c}\text { Nursing Technician } \\
(\text { (OR) })^{*}\end{array}$} & \multicolumn{2}{|c|}{$\begin{array}{c}\text { Nursing Technician } \\
(\mathrm{SI})^{\dagger}\end{array}$} & \multicolumn{2}{|c|}{$\begin{array}{c}\text { Nursing Technician } \\
(\text { (PR) })^{\ddagger}\end{array}$} \\
\hline & $\mathbf{n}$ & $\%$ & $\mathbf{n}$ & $\%$ & $\mathbf{n}$ & $\%$ & $\mathbf{n}$ & $\%$ \\
\hline 0580 - Urinary Catheterization & 18 & 2.03 & - & - & - & - & - & - \\
\hline 7892 - Transport: Interfacility & 49 & 5.52 & 68 & 3.45 & - & - & 2 & 0.84 \\
\hline 1806 - Self-Care Assistance: Transfer & 17 & 1.91 & 71 & 3.60 & 4 & 0.23 & - & - \\
\hline 6482 - Environmental Management: Comfort & 4 & 0.45 & 6 & 0.30 & - & - & 3 & 1.25 \\
\hline 2000 - Electrolyte Management & 9 & 1.01 & 19 & 0.96 & - & - & - & - \\
\hline 2260 - Sedation Management & - & - & 9 & 0.46 & - & - & 9 & 3.75 \\
\hline 6545 - Infection Control: Intraoperative & 19 & 2.14 & 542 & 27.47 & 412 & 23.82 & 25 & 10.40 \\
\hline 0842 - Positioning: Intraoperative & 14 & 1.58 & 28 & 1.42 & 1 & 0.06 & 1 & 0.42 \\
\hline 2870 - Postanesthesia Care & 6 & 0.69 & 11 & 0.56 & - & - & - & - \\
\hline
\end{tabular}




\begin{tabular}{|c|c|c|c|c|c|c|c|c|}
\hline \multirow{2}{*}{ Direct care interventions } & \multicolumn{2}{|c|}{ Nurse } & \multicolumn{2}{|c|}{$\begin{array}{l}\text { Nursing Technician } \\
(\mathrm{OR})^{*}\end{array}$} & \multicolumn{2}{|c|}{$\begin{array}{l}\text { Nursing Technician } \\
(\mathrm{SI})^{\dagger}\end{array}$} & \multicolumn{2}{|c|}{$\begin{array}{l}\text { Nursing Technician } \\
\left(\text { (PR) }{ }^{\ddagger}\right.\end{array}$} \\
\hline & $\mathbf{n}$ & $\%$ & $\mathbf{n}$ & $\%$ & $\mathbf{n}$ & $\%$ & n & $\%$ \\
\hline 2900 - Surgical Assistance & 49 & 5.52 & 306 & 15.51 & 1120 & 64.74 & 4 & 1.68 \\
\hline 2920 - Surgical Precautions & 41 & 4.62 & 103 & 5.22 & 87 & 5.03 & 51 & 21.24 \\
\hline 3500 - Pressure Management & - & - & 1 & 0.05 & - & - & - & - \\
\hline 3660 - Wound Care & 1 & 0.11 & 5 & 0.25 & 17 & 0.98 & - & - \\
\hline 3902 - Temperature Regulation: Intraoperative & 12 & 1.35 & 73 & 3.70 & - & - & - & - \\
\hline 4030 - Blood Products Administration & 2 & 0.22 & - & - & - & - & - & - \\
\hline 4130 - Fluid Monitoring & 1 & 0.11 & - & - & - & - & 2 & 0.84 \\
\hline 5270 - Emotional Support & - & - & 2 & 0.10 & - & - & - & - \\
\hline 5340 - Presence & 31 & 3.49 & 13 & 0.67 & - & - & 6 & 2.50 \\
\hline 6486 - Environmental Management: Safety & 2 & 0.22 & 10 & 0.50 & - & - & - & - \\
\hline 6654 - Surveillance: Safety & 76 & 8.56 & - & - & - & - & - & - \\
\hline 6680 - Vital Signs Monitoring & 1 & 0.11 & 1 & 0.05 & - & - & 34 & 14.16 \\
\hline 7140 - Family Support & 28 & 3.15 & - & - & - & - & - & - \\
\hline Subtotal & 380 & 42.79 & 1268 & 64.27 & 1641 & 94.86 & 137 & 57.08 \\
\hline
\end{tabular}

* OR - Operating Room; + SI - Surgical Instrumentation; ₹ PR - Patient Reception

Table 3 - Distribution of the indirect care interventions, carried out by nursing professionals during the transoperative period at the surgical center. Sao Paulo, SP, Brazil, 2011

\begin{tabular}{|c|c|c|c|c|c|c|c|c|}
\hline \multirow{2}{*}{ Indirect care interventions } & \multicolumn{2}{|c|}{ Nurse } & \multicolumn{2}{|c|}{$\begin{array}{l}\text { Nursing Technician } \\
\text { (OR) }\end{array}$} & \multicolumn{2}{|c|}{$\begin{array}{l}\text { Nursing Technician } \\
(\mathrm{SI})^{\dagger}\end{array}$} & \multicolumn{2}{|c|}{$\begin{array}{l}\text { Nursing Technician } \\
(\text { (PR) }\end{array}$} \\
\hline & $\mathbf{n}$ & $\%$ & $\mathbf{n}$ & $\%$ & n & $\%$ & $\mathbf{n}$ & $\%$ \\
\hline 7640 - Critical Path Development & 1 & 0.11 & - & - & - & - & - & - \\
\hline 7650 - Delegation & 76 & 8.56 & - & - & - & - & - & - \\
\hline 7710 - Physician Support & 11 & 1.24 & - & - & - & - & - & - \\
\hline 7760 - Product Evaluation & 2 & 0.22 & - & - & - & - & - & - \\
\hline 7820 - Specimen Management & 3 & 0.35 & 38 & 1.93 & 2 & 0.12 & - & - \\
\hline 7840 - Supply Management & 32 & 3.60 & 79 & 4.00 & 1 & 0.06 & 3 & 1.25 \\
\hline 7850 - Staff Development & 18 & 2.03 & 97 & 4.92 & 32 & 1.85 & 15 & 6.25 \\
\hline 7880 - Technology Management & 1 & 0.11 & 1 & 0.05 & 3 & 0.17 & - & - \\
\hline 7920 - Documentation & 166 & 18.69 & 342 & 17.33 & - & - & 46 & 19.17 \\
\hline 8140 - Shift Report & 63 & 7.09 & 44 & 2.23 & - & - & 5 & 2.08 \\
\hline Subtotal & 373 & 42.00 & 601 & 30.46 & 38 & 2.20 & 69 & 28.75 \\
\hline
\end{tabular}

* OR - Operating Room; + SI - Surgical Instrumentation; ₹ PR - Patient Reception

Table 4 - Distribution of work time spent by the nursing professionals with the domains of the NIC, at the surgical center. Sao Paulo, SP, Brazil, 2011

\begin{tabular}{|c|c|c|c|c|c|c|c|c|}
\hline \multirow{2}{*}{ Domains } & \multicolumn{2}{|c|}{ Nurse } & \multicolumn{2}{|c|}{$\begin{array}{l}\text { Nursing Technician } \\
(\mathrm{OR})^{*}\end{array}$} & \multicolumn{2}{|c|}{$\begin{array}{l}\text { Nursing Technician } \\
(\mathrm{SI})^{\dagger}\end{array}$} & \multicolumn{2}{|c|}{$\begin{array}{l}\text { Nursing Technician } \\
\text { (PR) }\end{array}$} \\
\hline & $\mathrm{n}$ & $\%$ & $\mathrm{n}$ & $\%$ & $\mathrm{n}$ & $\%$ & $\mathrm{n}$ & $\%$ \\
\hline Physiological Basic & 88 & 9.91 & 145 & 7.35 & 4 & 0.23 & 5 & 2.08 \\
\hline Physiological Complex & 154 & 17.34 & 1097 & 55.60 & 1637 & 94.62 & 92 & 38.33 \\
\hline Behavioral & 31 & 3.49 & 15 & 0.76 & - & - & 6 & 2.50 \\
\hline Safety & 81 & 9.12 & 21 & 1.06 & - & - & 34 & 14.17 \\
\hline Family & 28 & 3.15 & - & - & - & - & - & - \\
\hline Health System & 371 & 41.78 & 591 & 29.96 & 38 & 2.20 & 69 & 28.75 \\
\hline Subtotal & 753 & 84.79 & 1869 & 94.73 & 1679 & 97.05 & 206 & 85.83 \\
\hline
\end{tabular}

* OR - Operating Room; + SI - Surgical Instrumentation; ₹ PR - Patient Reception 


\section{Discussion}

Out of the 49 nursing interventions that were identified, 34 were classified as direct care interventions and 15 as indirect care interventions, in accordance with the NIC. Among the 280 validated activities, only 14 did not correspond with the NIC interventions; these were classified as associated activities or as personal activities. These findings are consistent with the study, using NIC within an orthopedic surgical unit, in which the NIC terminology was found to represent the full scope of the nursing work ${ }^{(17)}$.

Among the 51 interventions recommended by the NIC for surgical centers, the following were not identified in this study: autotransfusion (2830); preoperative coordination (2880); surgical preparation (2930); teaching: preoperative (5610); suturing (3620); laser precautions (6560); hypothermia induction (3790), and discharge planning (7370). However, other interventions that were identified and performed by the nursing team of the surgical center of ICESP were added: urinary catheterization (0580); postmortem care (1770); family support (7140); preceptor: student (7726); staff development (7850) and shift report (8140). Postmortem care (1770) and preceptor: student (7726) interventions were not observed by the researchers during the data collection period: the former because there were no deaths in the operating room and the latter because there were no undergraduate or postgraduate students present in the surgical center.

The most prevalent NIC domain was Physiological: Complex $(61.68 \%)$, with the direct care intervention Surgical Assistance (2900) (30.61\%); followed by the Health System domain (22.12\%), with the indirect care intervention Documentation (7920) (11.47\%). This finding is similar to other studies that have analyzed the workload distribution of nursing professionals, in different types of units, and identified as the most frequent indirect intervention was Documentation (7920).

The assistance provided by the nursing team at the surgical center included six domains of the NIC, revealing the wide range of care interventions for surgical patients. As expected, no interventions within the Community domain were observed in this study. It is important to highlight that interventions in domains relating to psychosocial care were infrequent, probably due to the short amount of time during which patients in the transoperative period remain awake.

Despite the low frequency of the observed associated activities, it was considered that these could have been performed by administrative personnel, under nursing supervision, in order to distribute the actions according to the specific competences of each professional.

Of concern was the short time that the professionals spent attending to their personal needs (4.66\%). We believe that this should serve as a warning sign to managers, because of the physical and emotional exhaustion which can result from an excessive workload. The short time allotted to personal needs results in a very high productivity (95.34\%) for the nursing team of the surgical center of ICESP; this may indicate a work

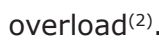

Productivity levels greater than $90 \%$ increase costs and decrease the quality of care ${ }^{(19)}$. In analyzing the data from this viewpoint, it is recommended that a review of the staffing level of nurses and nursing technicians should be conducted, to ensure the quality of the care provided and to protect the physical and mental health of these professionals.

\section{Conclusion}

The objective of this study was to analyze the workload distribution of nursing professionals' relating to interventions and activities, according to the NIC, during the transoperative period in a surgical center specializing in oncology.

Identification and classification of nursing interventions and activities, according to the NIC, and measurement of frequencies through the sampling technique of this study, enabled the assessment of workload distribution between the surgical centers' nursing teams during the transoperative period.

This study attests to the use of the NIC to identify the nursing staff workload in a surgical center specializing in oncology and is a more accurate indicator as it identified interventions/activities during the transoperative period.

Knowledge of the nursing intervention and activities that influence nursing workload contributes to the discussion regarding professional staffing levels that are appropriate for patients' care needs during the transoperative period. It also contributes to the measurement of nursing costs and, consequently, towards demonstrating the costeffectiveness of nursing professionals' participation in surgical care centers. Additional studies to link the NIC to patient outcomes, using a framework such as the Nursing Outcomes Classification, would also provide data to demonstrate the impact of nursing intervention on positive patient outcomes. 
Limitations to this study are in part based on the complexity of the topic investigated herein. These results reflect data from only one institution, which makes it impossible to generalize the data. Moreover, the datagathering period should be extended to increase the reliability of the measurements on nursing intervention and activities.

Nevertheless, the results presented are innovative and can support the beginning of the outline of an algorithm for care times according to the different requirements of surgical patients during the transoperative period. They can also provide a baseline for constructing computer software that can enable the calculation of nursing workloads within the surgical center.

Finally, it is critical to highlight that nursing is not merely a task-oriented profession. Although we believe that the NIC does indeed capture various dimensions of nursing workload, the time required for obtaining and considering critically important nursing knowledge which requires clinical judgment/reasoning skills must be considered within the overall workload. Further studies that link nursing workload to clinical judgments made by nurses, using the evidence-base of NANDA International's nursing diagnoses, and that seek to find a mechanism for including time in workload calculations to recognize the importance of assessment and of clinical judgment, it will be critical for a true representation of the workload of professional nursing practices.

\section{References}

1. Aiken LH. Economics of nursing. Policy Politics \& Nursing Practice 2008;9(2):73-9.

2. Fugulin FMT, Lima AFC, Castilho V, Bochembuzio L, Costa JA, Castro L. Cost of nursing staffing adequacy in a neonatal unit. Rev Esc Enferm USP. 2011;45(n. spe):1582-8.

3. Kiekkas P, Sakellaropoulos GC, Brokalaki H, Manolis E, Samios A, Skartsani C, et al. Association Between Nursing Workload and Mortality of Intensive Care Unit Patients. J Nurs Scholarsh. 2008;40(4):385-90.

4. Padilha KG, Sousa RMC, Queijo AF, Mendes AM, Miranda DR. Nursing Activities Score in the intensive care unit: Analysis of the related factors. Intensive Crit Care Nurs. 2008; 24(3):197-204.

5. Padilha KG, Sousa RMC, Kimura M, Miyadahira AMK, Cruz DALM, Vattimo MF, et al. Nursing workload in intensive care units: A study using the Therapeutic Intervention Scoring System-28 (TISS-28) Intensive Crit Care Nurs. 2007;23(3):162-9.
6. Holden RJ, Scanlon MC, Patel NR, Kaushal R, Escoto $\mathrm{KH}$, Brown RL, et al. A human factors framework and study of the effect of nursing workload on patient safety and employee quality of working life. BMJ Qual Saf. $2011 ; 20(1): 15-24$.

7. Duffield C, Diers D, O’Brien-Pallas L, Aisbett C, Roche $M$, King $M$, et al. Nursing staffing, nursing workload, the work environment and patient outcomes. Appl Nurs Res. 2011;24(4): 244-55.

8. Byrne G, Brady AM, Horan P, Macgregor C, Begley C. Assessment of dependency levels of older people in the community and measurement of nursing workload. J Adv Nurs. 2008; 60(1):39-49.

9. Brady AM, Byrne G, Horan P, Griffiths C, Macgregor C, Begley $\mathrm{C}$. Measuring the workload of community nurses in Ireland: a review of workload measurement systems. J Nurs Manage. 2007;15(5):481-9.

10. Aiken LH, Clarke SP, Sloane DM, Sochalski J, SilberJH. Hospital nurse staffing and patient mortality, nurse burnout, and job dissatisfaction. J Am Med Assoc. 2002; 288(16):1987-93.

11. Rafferty AM, Clarke SP, Coles J, Ball J, James P, McKee $M$, el al. Outcomes of variation in hospital nurse staffing in English hospitals: Cross-sectional analysis of survey data and discharge records. Int J Nurs Stud. 2007;44(2):175-82.

12. Carayon $P$, Gurses AP. A human factors engineering conceptual framework of nursing workload and patient safety in intensive care units. Intensive Crit Care Nurs. 2005;21(5):284-301.

13. Ghaferi AA, Birkmeyer JD, Dimick JB. Variation in Hospital Mortality Associated with Inpatient Surgery. N Engl J Med. 2009;361(14):1368-75.

14. Kane RL, Shamliyan TA, Mueller C, Duval S, Wilt TJ. The association of registered nurse staffing levels and patient outcomes: systematic review and meta-analysis. Med Care 2007;45(12):1195-204.

15. Cruz CW, Bonfim D, Gaidzinski RR, Fugulin FM, Laus AM. The use of Nursing Interventions Classification (NIC) in identifying the workload of nursing: an integrative review. Int J Nurs Knowl. [Internet]. Oct 2014 [acesso $18 \mathrm{dez} 2014$ ];25(3):15460. Disponível em: http://onlinelibrary.wiley. com/doi/10.1111/2047-3095.12031/abstract doi: 10.1111/2047-3095.12031

16. Bulechek GM, Butcher HK, Dochterman JM, Wagner C. Nursing Intervention Classification (NIC). 6th ed. St.Louis: Mosby Elsevier; 2013.

17. Cordova PB, Lucero RJ, Hyun S, Quinlan P, Price K, Stone PW. Using the Nursing Interventions Classification 
as a Potential Measure of Nurse Workload. J Nurs Care Qual. 2010;25(1):39-45.

18. Lucena, AF, Barros ALB L. Cross-mapping: an alternative to data analysis in nursing. Acta Paul Enferm. $2005 ; 18(1): 82-8$.

19. O'Brien-Pallas L, Thomson D, Hall LM, Ping KM, Wang S, Li X, MeyerR. Evidence-based standards for measuring nurse staffing and performance. Otawa, Ontário: Canadian Health Sciences; 2004. 